\title{
Role of potassium channels in female reproductive system
}

\author{
Jun-Mo Kim, MD, PhD', Ki-Sung Song, MS², Boqun $\mathrm{Xu}, \mathrm{MD}^{3}$, Tong Wang, MD \\ ${ }^{1}$ Department of Urology, ${ }^{2}$ Interdisciplinary Program in Biomedical Science, Soonchunhyang University, Bucheon Hospital, Bucheon, Korea, ${ }^{3}$ Department \\ of Cellular and Molecular Physiology, Yale University, School of Medicine, New Haven, CT, USA
}

Potassium channels are widely expressed in most types of cells in living organisms and regulate the functions of a variety of organs, including kidneys, neurons, cardiovascular organs, and pancreas among others. However, the functional roles of potassium channels in the reproductive system is less understood. This mini-review provides information about the localization and functions of potassium channels in the female reproductive system. Five types of potassium channels, which include inward-rectifying (Kir), voltage-gated (Kv), calcium-activated $\left(\mathrm{K}_{\mathrm{Ca}}\right)$, 2-pore domain $\left(\mathrm{K}_{2 \mathrm{p}}\right)$, and rapidly-gating sodium-activated (Slo) potassium channels are expressed in the hypothalamus, ovaries, and uterus. Their functions include the regulation of hormone release and feedback by Kir6.1 and Kir6.2, which are expressed in the luteal granulosa cells and gonadotropin-releasing hormone neurons respectively, and regulate the functioning of the hypothalamus-pituitary-ovarian axis and the production of progesterone. Both channels are regulated by subtypes of the sulfonylurea receptor (SUR), Kir6.1/SUR2B and Kir6.2/SUR1. Kv and Slo2.1 affect the transition from uterine quiescence in late pregnancy to the state of strong myometrial contractions in labor. Intermediate- and small-conductance $\mathrm{K}_{\mathrm{Ca}}$ modulate the vasodilatation of the placental chorionic plate resistance arteries via the secretion of nitric oxide and endothelium-derived hyperpolarizing factors. Treatment with specific channel activators and inhibitors provides information relevant for clinical use that could help alter the functions of the female reproductive system.

Keywords: Potassium channels; Gonadal steroid hormones; Ovary; Uterus; Placenta

\section{Introduction}

The maintenance of extracellular potassium concentration within a narrow range is vital for numerous cellular functions, particularly for maintaining the electrical excitability of heart and muscle cells [1]. The plasma potassium concentration is usually maintained within narrow limits (typically, 3.5 to $5.0 \mathrm{mmol} / \mathrm{L}$ ) through multiple mechanisms [2]. The functions of potassium channels are critical for urinary excretion of potassium ions. The long-term maintenance of potassium homeostasis is achieved by alterations in the renal excretion of potassium in response to variations in intake [3]. Fig. 1 shows that $90 \%$ of potassium that is derived from dietary intake is excreted by the kidney (up to $80 \mathrm{mEq} /$ day intake vs. $72 \mathrm{mEq} /$ day in the urine) to maintain normal potassium concentrations in the extracellular fluid (up to $70 \mathrm{mEq} /$ day in adults) [1]. In Korea, the recommended dietary intake of potassium in individuals above $12 \mathrm{yr}$ is 3,500 $\mathrm{mg}$; the World Health Organization recommends a similar intake. Intracellu- lar fluids contain approximately $98 \%$, or rather 3,600 mmol $(140 \mathrm{~g})$ of the potassium ions in the body, while the other $2 \%$ present in the extracellular compartment is usually maintained within a narrow range $(3.8-4.5 \mathrm{mEq} / \mathrm{L})$ in serum $[4,5]$. Since our ancestors could easily obtain potassium-rich fruit and vegetables, the recommended content of $15 \mathrm{~g} /$ day was

Received: 2020.03.10. Accepted: 2020.06.26.

Corresponding author: Tong Wang, MD

Department of Cellular and Molecular Physiology, Yale School of Medicine, 333 Cedar Street, P.O. Box 208026, New Haven, CT 06520-8026, USA

E-mail: tong.wang@yale.edu

https://orcid.org/0000-0001-7054-2540

Articles published in Obstet Gynecol Sci are open-access, distributed under the terms of the Creative Commons Attribution Non-Commercial License (http://creativecommons. org/licenses/by-nc/3.0/) which permits unrestricted non-commercial use, distribution, and reproduction in any medium, provided the original work is properly cited.

Copyright $\odot 2020$ Korean Society of Obstetrics and Gynecology 


\section{Obstetrics \& Gynecology Science}

Vol. 63, No. 5, 2020

easily exceeded. There are several types of highly evolved potassium channels in the kidney [4]. The balance in potassium ion concentration across the cell membrane is essential for maintaining the resting membrane potential and signal conduction in nerve and muscle cells via the repolarization of action potential. Potassium channels are pore-forming transmembrane (TM) proteins and are classified into 4 major families: calcium-activated, inward-rectifier, voltage-gated, and 2-pore-domain potassium channels [6]. Certain researchers classify ATP-sensitive potassium channels as a fifth family independent of inward-rectifier potassium channels $[7,8]$.

Potassium channels consist of 2 subunits: primary $a$-subunits and auxiliary $\beta$-subunits. The pore-forming subunits have 2-6 TM domains and the sensitivity of the channels to calcium, ATP, voltage, and oxygen among others is conferred by the a-subunits. Voltage-gated potassium channels ( $K_{v}$ channels) comprise of 6 TM domains, calciumactivated potassium channels ( $\mathrm{BK}_{\mathrm{Ca}}$ channels) have 6 or $7 \mathrm{TM}$ segments, and inward-rectifying potassium channels have 2 TM segments as a-subunits [9]. In contrast, $\beta$-subunits regulate the activities of the channels; e.g., SUR-subunits in Kir6. $X$ channels are involved in the regulation of insulin secretion. The various types of potassium channels are involved in controlling different phases of the action potential—while the majority of $\mathrm{K}_{\mathrm{v}}$ channels allow $\mathrm{K}^{+}$ion efflux when the membrane is depolarized, Kir channels conduct $\mathrm{K}^{+}$ions during hyperpolarization [10]. Table 1 outlines the details of calciumactivated $\left(\mathrm{K}_{\mathrm{Ca}}\right)$ and inward-rectifying (Kir) $\mathrm{K}_{\text {ATP }}$ potassium channel families and Table 2 outlines the details of voltagegated $\left(\mathrm{K}_{\mathrm{v}}\right)$ and the 2-pore domain $\left(\mathrm{K}_{2 \mathrm{p}}\right)$ potassium channel families. The well-known activators and inhibitors are also listed in the tables [11].

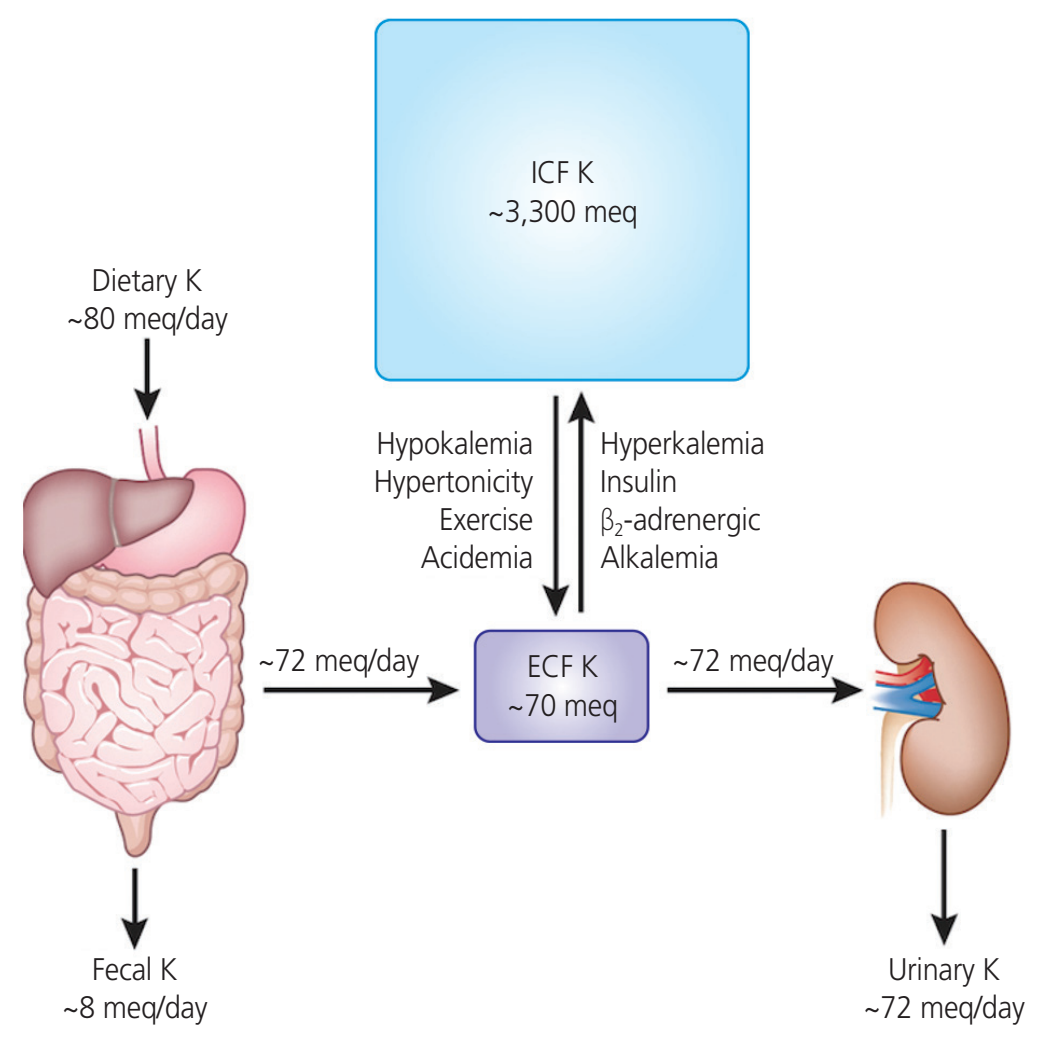

Fig. 1. The amounts of potassium of daily dietary intake, distribution in intracellular fluid (ICF) and extracelluler fluid (ECF), and daily fecal and urinary excretion. Most dietary potassium is excreted by the kidney (up to $80 \mathrm{mEq} /$ day intake vs. up to $72 \mathrm{mEq} / \mathrm{day}$ in the urine) to maintain normal potassium concentrations. Approximately $98 \%$ of potassium is present in the ICF (up to $3,300 \mathrm{mEq}$ ), while the other $2 \%$ present in the extracellular compartment (up to $70 \mathrm{mEq}$ ) which is usually maintained within a narrow range $(3.8-4.5 \mathrm{mEq} / \mathrm{L})$ in serum. Hypokalemia has many causes including: excessive potassium loss due to diarrhea, excessive sweating from exercise, abuse of alcohol, some diuretics, or laxatives. In contrast, hyperkalemia can be occurred due to acute kidney failure, chronic kidney disease, medication such as angiotensin II receptor blockers, angiotensin-converting enzyme inhibitors, or beta blockers, and dehydration or excessive potassium supplements. 


\section{Obstetrics \& Gynecology Science}

Jun-Mo Kim, et al. $K$ channels in female reproductive system

Notably, the potassium channels participate not only in the regulation of membrane potential but also in various cellular functions, including volume regulation, cell proliferation, cell migration, angiogenesis, and apoptosis [6]. This mini-review focuses on the multiple potassium channels associated with the cells of the female reproductive system, and discusses their action on the hypothalamus-pituitary-ovarian axis for the regulation of progesterone production from granulosa

Table 1. Summary of calcium activated $\left(K_{C_{a}}\right)$ and inwardly-rectifying (Kir) $K_{\text {ATP }}$ potassium channel families, activators and inhibitors

\begin{tabular}{|c|c|c|c|}
\hline \multicolumn{2}{|c|}{$\mathrm{K}_{\mathrm{ca}}$ channels (8 isoforms \& 5 subfamilies): $\mathrm{BK}_{\mathrm{Ca}}, \mathrm{SK}$, IK } & \multicolumn{2}{|c|}{ Kir channels (15 isoforms \& 7 subfamiles): $K_{\text {ATP }}$} \\
\hline HGCN & IUPHAR & HGCN & IUPHAR \\
\hline KCNMA1 & $\mathrm{K}_{\mathrm{Ca}} 1.1$ & KCNJ1 & Kir1.1 \\
\hline KCNN1-3 & $\mathrm{K}_{\mathrm{Ca}} 2.1-\mathrm{K}_{\mathrm{Ca}} 2.3$ & $\mathrm{KCNJ} 2, \mathrm{~J} 12, \mathrm{~J} 4 \mathrm{\&} \mathrm{J} 14$ & Kir2.1-Kir2.4 \\
\hline KCNN4 & $\mathrm{K}_{\mathrm{Ca}} 3.1$ & KCNJ3, J6, J9 \& J5 & Kir3.1-Kir3.4 \\
\hline KCNT1 \& T2 & $\mathrm{K}_{\mathrm{Ca}} 4.1 \& \mathrm{~K}_{\mathrm{Ca}} 4.2$ & KCNJ10 \& J15 & Kir4.1 \& Kir4.2 \\
\hline \multirow[t]{3}{*}{ KCNU1 } & $K_{C a} 4.1$ & KCNJ16 & Kir5.1 \\
\hline & & KCNJ8 \& J11 & Kir6. 1 \& Kir6.2 \\
\hline & & KCNJ13 & Kir7.1 \\
\hline \multicolumn{2}{|c|}{ Channel opener for $\mathrm{K}_{\mathrm{ca}}$ : NS1619 } & \multicolumn{2}{|c|}{ Channel opener for $K_{\text {ir: }}$ Pinacidil, cromakalim, aprikalim (Kir6.x) } \\
\hline \multicolumn{2}{|c|}{ Channel blocker for $\mathrm{K}_{\mathrm{ca}}$ : Iberiotoxin, apamin, charybdotoxin } & \multicolumn{2}{|c|}{$\begin{array}{l}\text { Channel blocker for } \mathrm{K}_{\mathrm{ir}} \text { : Tetraethylammonium (TEA), 4-aminopyridine } \\
\text { (4-AP), glibenclamide, tolbutamide }\end{array}$} \\
\hline
\end{tabular}

The table is adopted from reference [11].

Table 2. Summary of voltage gated $\left(K_{v}\right)$ and the 2-pore domain $\left(K_{2 p}\right)$ potassium channel families, activators and inhibitors

\begin{tabular}{|c|c|c|c|}
\hline \multicolumn{2}{|c|}{$\mathrm{K}_{\mathrm{V}}$ channels (42 isoforms $\& 12$ subfamilies) } & \multicolumn{2}{|c|}{$\mathrm{K}_{2 \mathrm{P}}$ channels (15 isoforms) } \\
\hline HGCN & IUPHAR & HGCN & IUPHAR \\
\hline KCNA1-A0 & $K_{v} 1.1-K_{v} 1,10$ & KCNK1 & $\mathrm{K}_{2 \mathrm{p}} 1.1$ \\
\hline KCNB1-B2 & $K_{\mathrm{v}} 2.1 \& K_{\mathrm{v}} 2.2$ & KCNK2 & $K_{2 p} 2.1$ \\
\hline KCNC1-C4 & $K_{v} 3.1-K_{v} 3.4$ & KCNK3 & $K_{2 p} 3.1$ \\
\hline KCND1-D3 & $K_{v} 4.1-K_{v} 4.3$ & KCNK4 & $K_{2 p} 4.1$ \\
\hline KCNF1 & $K_{V} 5.1$ & KCNK5 & $K_{2 p} 5.1$ \\
\hline KCNG1-G4 & $K_{v} 6.1-K_{v} 6.4$ & KCNK6 & $K_{2 p} 6.1$ \\
\hline KCNQ1-Q5 & $K_{v} 7.1-K_{v} 7.5$ & KCNK7 & $\mathrm{K}_{2 \mathrm{p}} 7.1$ \\
\hline KCNV1\& V2 & $K_{\vee} 8.1 \& K_{v} 8.2$ & KCNK9 & $K_{2 p} 9.1$ \\
\hline KCNS1-3 & $\mathrm{K}_{\mathrm{v}} 9.1-\mathrm{K}_{\mathrm{v}} 9.3$ & KCNK10 & $K_{2 P} 10.1$ \\
\hline $\mathrm{KCNH} 1 \& \mathrm{H} 5$ & $K_{V} 10.1 \& K_{V} 10.2$ & KCNK12 & $\mathrm{K}_{2 \mathrm{P}} 12.1$ \\
\hline $\mathrm{KCNH} 2, \mathrm{H} 6$, and $\mathrm{H} 7$ & $K_{v} 11.1-K_{v} 11.3$ & KCNK13 & $K_{2 P} 13.1$ \\
\hline \multirow[t]{4}{*}{$\mathrm{KCNH} 8, \mathrm{H} 3$, and $\mathrm{H} 4$} & $K_{V} 12.1-K_{v} 12.3$ & KCNK15 & $K_{2 P} 15.1$ \\
\hline & & KCNK16 & $K_{2 P} 16.1$ \\
\hline & & KCNK17 & $K_{2 p} 17.1$ \\
\hline & & KCNK18 & $K_{2 p} 18.1$ \\
\hline \multicolumn{2}{|c|}{$\begin{array}{l}\text { Channel opener for } K_{v} \text { : Correolide }\left(K_{v} 1.5\right) \text {, Stromatoxin-1 }\left(K_{v} 2.1\right) \text {, } \\
\text { Flupirtine }\left(K_{v} 7\right) \text { PD118057, NS1643 }(\mathrm{KCNH})\end{array}$} & \multicolumn{2}{|c|}{$\begin{array}{l}\text { Channel opener for } \mathrm{K}_{2 \mathrm{p}} \text { : Arachidonic acid (TREK-1), volatile } \\
\text { anesthetics (isoflurane) }\end{array}$} \\
\hline \multicolumn{2}{|c|}{$\begin{array}{l}\text { Channel blocker for } K_{v}: 4-A P\left(K_{v}\right) \text {, phrixotoxin-2 }\left(K_{v} 4\right) \text {, Linopirdine } \\
\left(K_{v} 7\right) \text {, dofetilide, E4031, Be-KM1 }(K C N H)\end{array}$} & \multicolumn{2}{|c|}{$\begin{array}{l}\text { Channel blocker for } \mathrm{K}_{2 p} \text { : Fluphenazine, L-methionine (TREK-1), SSRI } \\
\text { antipsychotics (haloperidol) }\end{array}$} \\
\hline
\end{tabular}

The table is adopted from reference [11] 


\section{Obstetrics \& Gynecology Science}

Vol. 63, No. 5, 2020

cells (GCs) in the ovary, myometrial relaxation in the uterus during pregnancy, the induction of uterine contractions in labor, and the modulation of human chorionic gonadotropin (hCG) production in the syncytiotrophoblast in the placenta $[5,12,13]$.

\section{Expression and roles of potassium channels in the ovary}

The ovary facilitates the production and maintenance of oocytes and supports the secretion of female sex hormones, which is essential for the regulation of puberty and pregnancy and determines the reproductive lifespan [14]. The ovary is protected by 3 outer layers: germinal epithelium, connective tissue capsule, and tunica albuginea. The outer cortex and inner medulla are located inside the ovary. Ovarian follicles at various stages of maturation are present in the ovarian cortex, and oocytes or female germ cells are present in each follicle. From puberty, the development and degeneration of follicles from the primordial follicle stage to the corpus luteum is influenced by follicle-stimulating hormone (FSH). The follicle primarily consists of oocytes and granulosa; progesterone is produced from luteinized GCs and by the corpus luteum in the ovary in the non-pregnant state. Progesterone concentrations peak 7-8 days after ovulation and rapidly reduce along with the degeneration of the corpus luteum. Progesterone inhibits the synthesis of gonadotropin-releasing hormone $(\mathrm{GnRH})$ to prevent the maturation of other follicles and prepares the body for a possible pregnancy. If fertilization does not occur, the corpus luteum degenerates and the follicle is excreted via menstrual bleeding [15]. The ovulation of mature follicles in the ovary is induced by a preovulatory surge in the levels of luteinizing hormone $(\mathrm{LH})$, and subsequently, estrogen is secreted by the GCs of the ovarian follicles and the corpus luteum. The concentrations of $\mathrm{LH}$ and FSH secreted by the pituitary gland and estradiol secreted by the follicles peak during ovulation in the menstrual cycle [15].

In the ovary, the $\mathrm{K}_{\text {ATP }}$ potassium channels and the $\mathrm{BK}_{\mathrm{Ca}}$ channels participate in the regulation of progesterone secretion, and the intracellular potassium and calcium concentrations affect the secretion of progesterone [16]. $\mathrm{BK}_{\mathrm{Ca}_{\mathrm{a}}}$ channels induce the repolarization of the plasma membrane and play an important role in the cellular response depending on the $\mathrm{Ca}^{2+}$ concentration. The acetylcholinergic agonist carbachol and oxytocin increase intracellular $\mathrm{Ca}^{2+}$ concentration in cultured human granulosa-lutein cells. The intracellular calcium signal affects progesterone release in lutein- $\mathrm{GCs}$ via $\mathrm{BK}_{\mathrm{Ca}}[16-$ 18]. hCG stimulates the release of oxytocin, which, along with acetylcholine, acts as an ovarian signaling molecule. Kunz et al. [16] reported that the activation of the $\mathrm{BK}_{\mathrm{Ca}}$ channels in GCs is generally necessary for endocrine function, and $\mathrm{BK}_{\mathrm{Ca}}$ channel blockade using iberiotoxin causes a marked reduction in hCG-stimulated progesterone secretion. Notably, hCG does not play a role in $\mathrm{BK}_{\mathrm{Ca}}$ activation; acetylcholine and oxytocin, which are local neuroendocrine substances released by GCs, participate in this process by causing a transient increase in the intracellular $\mathrm{Ca}^{2+}$ concentrations [19]. In summary, the activities of the $\mathrm{BK}_{\mathrm{Ca}}$ channel in $\mathrm{GCs}$ is mediated by intra-ovarian signaling involving neurotransmitters (e.g., acetylcholine) and peptide hormones (e.g., oxytocin). Traut et al. [20] reported the expression (in vitro and ex vivo) of several classes of $K_{C_{a}}$ channels (IK, SK, and BK) in human GCs, which participate in gonadotropin-stimulated sex steroid hormone production.

In addition to the intracellular calcium levels, the intracellular potassium levels also affect progesterone secretion from luteal cells [21]. Typical $K_{\text {ATP }}$ channels consist of an inwardrectifier $\mathrm{K}^{+}$ionophore (Kir6. $\mathrm{x}$ ) and a sulfonylurea receptor (SURx); there are 2 Kir6.x isoforms (Kir6.1 and 6.2), and 3 SUR isoforms (SUR1, SUR2A, and SUR2B). Although $6 \mathrm{com}$ binations of Kir6.x and SURx can be formed, only 4 types of $K_{\text {ATP }}$ channel have been reported: those found in pancreas $\beta$-cells (SUR1/Kir6.2), cardiac and skeletal muscles (SUR2A Kir6.2), smooth muscles (SUR2B/Kir6.2), and vascular smooth muscles (SUR2B/Kir6.1) [22]. Of these, only Kir6.1/SUR2B is detected in the corpus luteum of the ovary and myometrium of the rat, while the placenta expresses Kir6.1 with SUR1 and SUR2B [23]. These ovarian $K_{\text {ATP }}$ channels are involved in the production of progesterone in luteinized GCs [5]. The $\mathrm{K}_{\text {ATP }}$ inhibitor glibenclamide triggers the depolarization of the plasma membrane induced by the blockage of the $K_{\text {ATP }}$ channels; it reduces hCG-induced progesterone production in ovarian GCs [5]. However, the exact underlying mechanism remains unclear. Other ion channels, including $\mathrm{K}_{v} 4.2$ (KCND2) and L-type and T-type voltage-dependent $\mathrm{Ca}^{2+}$ channels and a $\mathrm{K}_{\text {ATP }}$-independent progesterone production process are also involved in hormone regulation $[24,25]$. Therefore, progesterone production is likely regulated via complex physiological processes. 


\section{Obstetrics \& Gynecology Science}

Jun-Mo Kim, et al. $\mathrm{K}$ channels in female reproductive system

\section{Expression and role of $\mathbf{K}_{\text {ATP }}$ channels in pulsatile secretion of gonadotropin- releasing hormone in the hypothalamus}

Progesterone secretion is mediated by the Kir6.1/SUR2B $K_{\text {ATP }}$ channel subtype in the ovary. $K_{\text {ATP }}$ channels are also involved in modulating the excitability of GnRH neurons in an estrogen-sensitive manner (Fig. 2). The pancreatic $\beta$-cell subtype of channels containing Kir6.2/SUR1 subunits is the $K_{\text {ATP }}$ channel subtype that is predominantly expressed in $\mathrm{GnRH}$ neurons in the hypothalamus [26]. The $\mathrm{K}_{\text {ATP }}$ channel Kir6.2/SUR1 modulates the pulsatile release of $\mathrm{GnRH}$, and negative feedback from ovarian steroids affects the release of hormones in the hypothalamus and pituitary by altering the activity of the
$\mathrm{K}_{\text {ATP }}$ channels. The Kir6.2 mRNA levels in the preoptic area responds to treatment with both $\mathrm{E} 2$ and progesterone. The $\mathrm{K}_{\text {ATP }}$ channel blocker tolbutamide enhances the frequency of pulsatile GnRH release under steroid treatment [27]. In contrast, the $\mathrm{K}_{\text {ATP }}$ channel activator diazoxide prevents the increase in the frequency of the LH pulse. As the Kir6.2/SUR1 subtype has a sulfonylurea receptor, this channel is activated by diazoxide, while it is blocked by sulfonylureas, including glibenclamide and tolbutamide [28]. Zhang et al. [26] reported that the glucose concentration and the presence of glucokinases also influence the excitability of GnRH neurons; whereas GnRH neurons are excited in high glucose concentrations, neuron excitability is inhibited in conditions of low glucose concentrations, such as starvation. Glucokinase

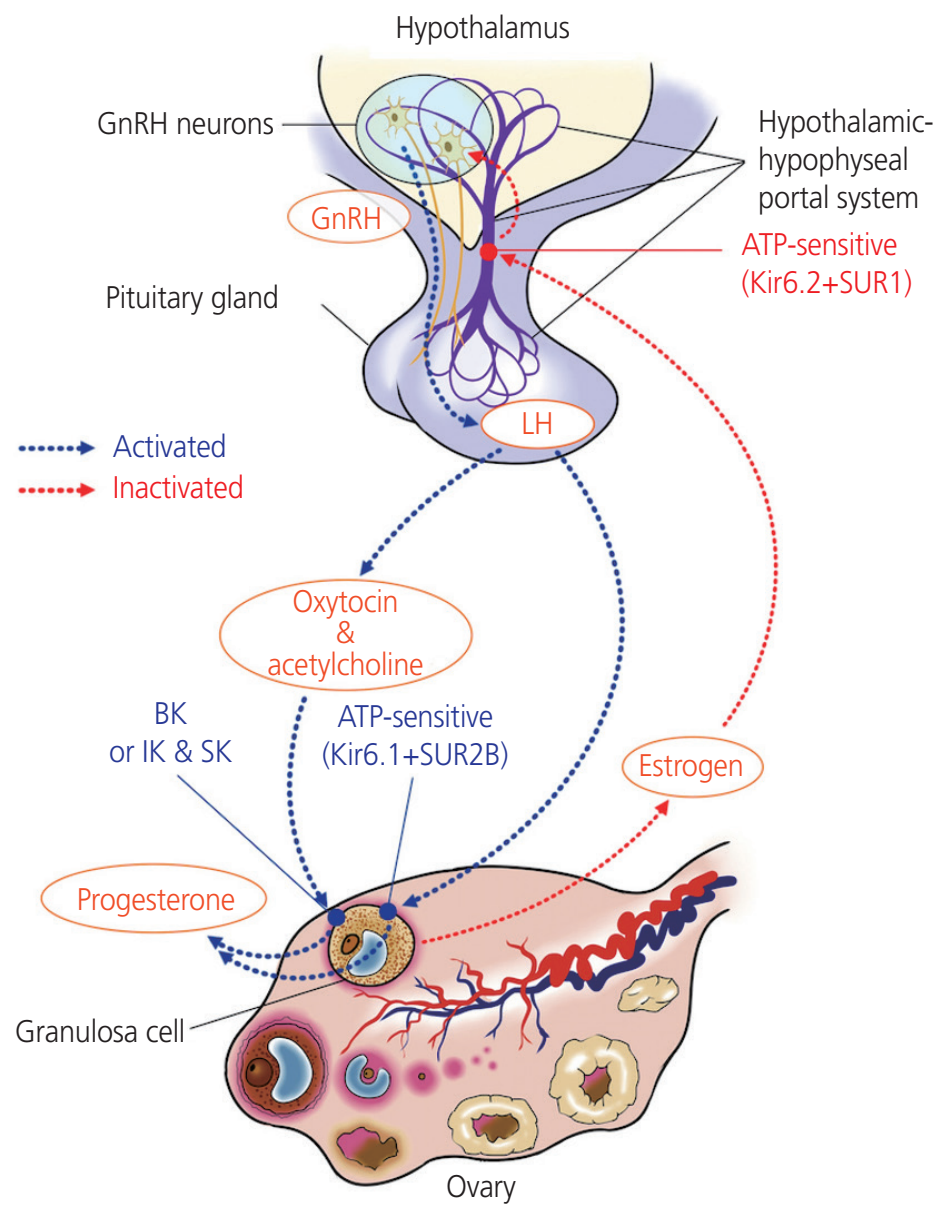

Fig. 2. Involvement potassium channels in hypothallus-pituitary-ovarian axis. While progesterone secretion is mediated by the Kir6.1/ SUR2B, $K_{\text {ATP }}$ channels subtype in the ovary, Kir6.2/SUR1 subunits is predominantly expressed in gonadotropin-releasing hormone (GnRH) neurons in the hypothalamus. The $\mathrm{K}_{\text {ATP }}$ channel Kir6.2/SUR1 modulates the pulsatile release of GnRH, and activity of the $\mathrm{K}_{\text {ATP }}$ channels responds to negative feedback from ovarian steroids-E2 and progesterone. The acetylcholine and oxytocin increase intracellular $\mathrm{Ca}^{2+}$ con- $^{2}$ centration in lutein-granulosa cells, the intracellular calcium signal affects progesterone release via BK $\mathrm{Ca}_{\text {. }}$ human chorionic gonadotropin stimulates the release of oxytocin, which, along with acetylcholine, acts as an ovarian signaling molecule. LH, luteinizing hormone. 


\section{Obstetrics \& Gynecology Science}

Vol. 63, No. 5, 2020

facilitates the phosphorylation of glucose to glucose-6-phosphate and is expressed in GnRH neurons. While Kir6.2 and SUR1 transcripts were found to be expressed in all neuronal cells, $66.7 \%$ of neuronal pooled cells expressed glucokinase mRNA. This suggests that glucokinase plays a role in regulating $\mathrm{GnRH}$ release via the $\mathrm{K}_{\text {ATP }}$ channels [26].

Potassium channels in GnRH neurons form a rich substrate for the modulation of activity. As 2 main components of voltage-gated potassium channel currents in cells, both the slowly inactivating potassium current $\left(I_{K}\right)$ and the fast inactivating A-type potassium current $\left(I_{A}\right)$ are generated in $\mathrm{GnRH}$ neurons. In recent studies, estradiol was shown to suppress both $I_{K}$ and $I_{A}$, these voltage-gated potassium conductance are largely responsible for the overall excitability and discharge activity in GnRH neurons [29-31]. The expression of genes encoding potassium channel proteins is altered in $\mathrm{GnRH}$ neurons at different stages of estrus in mice [32].

\section{Expression and role of potassium channels in the uterus}

The human uterus expands drastically during pregnancy owing to uterine smooth muscle hypertrophy, and the myometrium is one of the strongest uterine muscles that facilitates birth $[33,34]$. The uterus does not play any major role during pregnancy. Uterine quiescence during pregnancy is necessary for preventing preterm labor. Potassium efflux leads to the repolarization of the plasma membrane, which is responsible for maintaining the resting membrane potential. Inadequate repolarization of smooth muscle cells in the myometrium can lead to aberrant uterine activities, such as dystocia, preterm labor, and post-term labor [12]. The myometrium expresses several types of potassium channels, including $B K_{C a}, K_{A T P}$ small-conductance $\mathrm{Ca}^{2+}$-sensitive, voltage-gated, and 2-pore potassium channels [12]. The role of each type of potassium channel in the regulation of basal myometrial contractility and their contribution to molecular expression varies depending on the gestational stage [35].

$\mathrm{BK}_{\mathrm{Ca}}$ channels play a prominent role in inducing smooth muscle relaxation as they mediate the depolarization of the plasma membrane and contribute to the generation of approximately $35 \%$ of the total cell repolarizing potassium current [36]. The potassium current density in term mouse myometrium was observed to decrease significantly. The functional importance of the $\mathrm{BK}_{\mathrm{Ca}}$ channels decreases as a result of several factors, including a change in surface negative charges, decreased channel density, a positive shift in voltage-activation relation, and reduced sensitivity to calcium ions $[24,37]$. Furthermore, $\mathrm{BK}_{\mathrm{Ca}}$ channels are replaced by smaller conductance delayed rectifier channels in the abovementioned period; these remove the noises in the current and generate a smooth current that requires limited rectification [36]. However, there is another explanation for the turnover from uterine quiescence to the state of uterine contraction. First, the sensitivity of $\mathrm{BK}_{\mathrm{Ca}}$ to the intracellular calcium and voltage levels changes owing to alternative splicing of transcripts of the $\mathrm{BK}_{\mathrm{Ca}}$ channel, which is accompanied by post-translational modifications as well. Second, protein kinases exert different modulatory effects based on the gestational stage. Third, $\mathrm{Ca}^{2+}$ levels increase during pregnancy $[37,38]$. Notably, the differences in the regulation of channel transcripts implies that different populations of channels exist in the myometrium; this alteration in transcripts during pregnancy may be regulated by sex hormones $[21,38]$. In particular, the expression of $\beta 1$-subunit transcripts is partially regulated by estrogen and it is observed to peak in early pregnancy [39]. The regulatory $\beta$-subunit helps modulate uterine excitability by exhibiting sensitivity to both $\mathrm{Ca}^{2+}$ and voltage during gestation [37].

As $\mathrm{BK}_{\mathrm{Ca}}$ channels play a prominent role in myometrial contraction, several agents that activate and inhibit these channels, including $\beta$-adrenoceptor agonists, relaxin, hCG, and nitric oxide (NO), have been studied based on their role in controlling myometrial contraction [35]. Notably, although the $\mathrm{BK}_{\mathrm{Ca}}$ channel is the most abundant potassium channel in the myometrium and contributes to the regulation of myometrial functions, it does not play a role in the regulation of basal or uterine relaxation during late pregnancy or labor $[35,40]$. The BK $_{\mathrm{Ca}}$ channels are activated by NS1619, a benzimidazole derivate that promotes the activation of $\mathrm{BK}_{\mathrm{Ca}}$ channels; the administration of this agent did not significantly affect the contractile activity in human term-pregnant myometrium when oxytocin was secreted [41]. These results suggest that although $\mathrm{BK}_{\mathrm{Ca}}$ channels play a more significant role than other potassium channels in myometrial relaxation during the non-pregnancy period and in early gestation, the significance of their regulation is lesser in late gestation.

Instead of the $\mathrm{BK}_{\mathrm{Ca}}$ channel, the $\mathrm{K}_{\text {ATP }} \mathrm{K}_{\mathrm{V}}$ and Slo2.1 (rapidly-gating sodium-activated) potassium channels affect the 


\section{Obstetrics \& Gynecology Science}

Jun-Mo Kim, et al. $K$ channels in female reproductive system

transition from uterine quiescence in late pregnancy to the state of active contractions that aids the expulsion of the fetus in labor $[35,41,42]$. The intracellular $\mathrm{Na}^{+}, \mathrm{K}^{+}$, and $\mathrm{Ca}^{2+}$ ions and the ion channels are involved in the regulation of uterine relaxation and contraction. The Kir6.1/SUB2B $K_{\text {ATP }}$ channel is the predominant subtype in the myometrium and ovary [43]. The expression patterns of the $\mathrm{BK}_{\mathrm{Ca}}$ and $\mathrm{K}_{\mathrm{ATP}}$ channels are similar in each gestational stage, while the expression of Kir6.1 and SUR2B transcripts is significantly higher in the non-pregnant state than in late pregnancy before or during labor [43]. The $K_{\text {ATP }}$ channel activator pinacidil inhibits oxytocin-induced uterine contractions (both in terms of amplitude and frequency) in the myometrium in late pregnancy and in non-pregnant women; its effect was attenuated in the laboring myometrium owing to the differences in expression during gestation and labor [41].

The hyperpolarization of the plasma membranes of myometrial cells depends on the $\mathrm{K}^{+}$efflux for the maintenance of uterine quiescence, while the depolarization of the membrane potential owing to increased $\mathrm{Na}^{+}$influx is essential for countering uterine contractions by myocytes. $\mathrm{K}_{\mathrm{Na}}$ channels, which are high-conductance $\mathrm{K}^{+}$channels activated by $\mathrm{Na}^{+}$, require high concentrations of intracellular $\mathrm{Na}^{+}$instead of $\mathrm{Ca}^{2+}$ ions. Recently, Ferreira et al. [42] reported that oxytocin could regulate myometrial smooth muscle cell excitability via the $\mathrm{Na}^{+}$-activated Slo2.1 $\mathrm{K}^{+}$channel. The peptide-hormone oxytocin regulates the transition from uterine quiescence to contraction. Slick, a rapidly-gating sodium-activated potassium channel, induces $\mathrm{K}^{+}$efflux and opposes $\mathrm{Na}^{+}$influx via NALCN ( $\mathrm{Na}^{+}$leak channel, non-selective) at low levels of oxytocin [42]. However, when the levels of oxytocin increase at the end of pregnancy and it binds to its receptors, protein kinase $C$ is activated and SLO2.1 expression is inhibited. As a result, after $\mathrm{K}^{+}$efflux is reduced, the voltage-dependent $\mathrm{Ca}^{2+}$ channels are activated. When $\mathrm{Ca}^{2+}$ influx occurs and actinmyosin cross-bridging is initiated, myometrial contractility is augmented [42].

Small-conductance $\mathrm{Ca}^{2+}$-sensitive and voltage-insensitive potassium channels (SK), voltage-gated potassium channels $\left(K_{\mathrm{v}}\right)$, and 2-pore potassium channels are also expressed in the myometrium $[44,45]$. While small-conductance $\mathrm{K}^{+}$ $\left(\mathrm{SK}_{\mathrm{Ca}_{\mathrm{a}}}\right)$ channels and intermediate-conductance calciumactivated $\mathrm{K}^{+}\left(\mathrm{IK}_{\mathrm{Ca}}\right)$ channels are expressed in smooth muscle cells, including those of the myometrium, $\mathbb{I}_{C_{\mathrm{a}}}$ channels are primarily expressed in immune/inflammatory cells. The role of $\mathrm{IK}_{\mathrm{Ca}}$ channels in the myometrium has not been studied thoroughly [46-48]. Dimethylamine-nitric oxide (DEA/NO) inhibits myometrial contraction via a NO-induced relaxation mechanism. Apamin and scyllatoxin specifically block $\mathrm{Ca}^{2+}$ dependent apamin-sensitive $\mathrm{K}^{+}$channels $\left(\mathrm{SK}_{\mathrm{ca}} 1\right.$ to $\mathrm{SK}_{\mathrm{Ca}} 3$ ); the administration of $10 \mathrm{nM}$ apamin or scyllatoxin could completely inhibit the DEA/NO-induced relaxation of the myometrium [45]. This indicates that the participation of the $\mathrm{SK}_{\mathrm{Ca}}$ channels in NO-induced myometrial relaxation, especially in the overexpression of the $\mathrm{SK}_{\mathrm{Ca}^{3}} 3$ isoform, results in uterine dysfunction and delayed parturition [49]. In mice, the expression of the $\mathrm{SK}_{\mathrm{Ca}} 3$ channel decreases from the midgestational stages; sensitivity of this channel to apamin also reduces from late gestation. $\mathrm{SK}_{\mathrm{ca}} 3$ immunoreactivity was also observed in telocytes, formerly referred to as interstitial cells of Cajal or interstitial Cajal-like cells (ICLC), in non-pregnant myometrium, as well as in the glandular and luminal endometrial laminal epithelia in rats $[46,50,51]$. Although similar ICLC have been observed in rodent and human myometrial tissue, the functional role of these cells in the uterus remains unclear [52].

$\mathrm{K}_{\mathrm{V}}$ channels are the most diverse of potassium channels. The a-subunits of voltage-gated $K_{v}$ channels form the conductance pore and there are 12 classes and 40 types of a-subunits of $K_{v}$ channels. Voltage-gated $K_{v}$ channels are blocked by 4-aminopyridine (4-AP) or tetraethylammonium (TEA). The administration of both 1 and $5 \mathrm{mM}$ 4-AP significantly enhanced myometrial contractility in the nonpregnant, as well as mid- and late-pregnant myometrium [35]. These results indicate that voltage-gated $K_{v}$ channels contribute to uterine quiescence during mid to late pregnancy. Although treatment with TEA and 4-AP did not affect the contraction interval, the duration and amplitude of myometrial contractions were increased in both cases. The blockade response of Kv channels by 4-AP is not mediated by $\mathrm{BK}_{\mathrm{Ca}}$ channels of the endometrium and nerves in the myometrium [44]. It has been suggested that several different $K_{V}$ channel subtypes are present in the myometrium of both non-pregnant and term-pregnant mice. Myometrial contractions in non-pregnant mice were induced even at surprisingly low concentrations of 4-AP [53]. The $\mathrm{K}_{v} 4.3$ channel is not expressed in term-pregnant tissues. Phrixotoxin-2, which is a $\mathrm{K}_{v} 4.2 / \mathrm{K}_{v} 4.3$ blocker, induced contractions in nonpregnant myometrium, whereas the same was not induced in pregnant myometrium [44]. The genes encoding voltage- 


\section{Obstetrics \& Gynecology Science}

Vol. 63, No. 5, 2020

gated $K_{v}$ channels can be categorized into 9 families, named KCNA to KCNV gene families (Table 2). Two types of $K_{v}$ channels encoded by members of the KCNQ $\left(\mathrm{K}_{\mathrm{v}} 7\right)$ and $\mathrm{KCNH}$ $\left(K_{v} 11\right)$ gene families appear to act as key regulators of uterine contractility and may serve as novel therapeutic targets [52]. All isoforms of KCNQ are expressed in non-pregnant mice, with KCNQ1 (Kv7.1) as the dominant form [54]. The KCNQ and KCNE isoforms are expressed in early and late gestational stages in mice as well, the majority of KCNQ isoforms are upregulated in late pregnancy [54]. KCNE is a type of $\beta$-subunit associated with voltage-gated KCNQ a-subunits. These findings suggest that instead of facilitating the maintenance uterine quiescence in early pregnancy, these proteins primarily regulate myometrial contractility in the late stages of pregnancy. All KCNQ genes, except KCNQ5, were also observed to be expressed in human term myometrium. Flupirtine and retigabine, which are activators to the KCNQencoded $\mathrm{K}^{+}$channel $(\mathrm{K} 7)$, rapidly inhibited spontaneous and oxytocin-mediated myometrial contractility by $40-70 \%$ [54]. Ether-à-go-go-related genes or ERGs (ERG1-3) are members of the KCNH gene family (KCNH1-3). The ERG-encoded channel blockers dofetilide, E4031, and Be-KM1 increased oxytocin-mediated contractions in mouse myometrium, while the ERG activators PD118057 and NS1643 inhibited spontaneous contraction [55]. In summary, although several types of $K_{v}$ channels are expressed in uterine myometrium, there are contradictory results with respect to their upregulation or downregulation based on the gestational stage. K7 (KCNQ) and $\mathrm{K} 11(\mathrm{KCNH})$ channels play central roles in regulating myometrial activity at term and are possible targets for tocolytic agents in preterm labor [54].

The TWIK-related $\mathrm{K}^{+}$(TREK-1) channel is a 2-pore $\mathrm{K}^{+}$channel. TREK-1 is a stretch-activated tetraethyl ammoniuminsensitive $\mathrm{K}^{+}$channel that is sensitive to $\mathrm{pH}$, hypoxia, stretching, temperature, phosphorylation, and NO [56]. This channel is expressed in human myometrium, particularly during pregnancy. Its expression is upregulated during pregnancy and is induced upon stretching [57]. The TREK-1 channel plays a role in the regulation of uterine contractions. The TREK-1 activator arachidonic acid was observed to reduce uterine contractions, while the TREK-1 blocker L-methionine exerted the opposite effect. Interestingly, this response is related to the effect of progesterone on uterine relaxation. Both progesterone and arachidonic acid were observed to exert similar effects on TREK-1 activity. The progesterone- induced inhibition of uterine contraction was reversed in the presence of the TREK-1 inhibitor L-methionine [33]. Furthermore, since the expression and activity of this channel are essentially induced in response to uterine wall stretching, TREK1 may play a significant role in the determination of the type of pregnancy. Different TREK-1 expression patterns and activities in preterm versus term and in singleton versus twin pregnancies may help explain the differences in the uterine contractile response in each case [58].

\section{Expression of potassium channels in the placenta}

The placenta partakes in gas exchange, nutrient delivery, and waste transfer between the mother and fetus and has immunological and metabolic functions. Chorionic villi are in contact with maternal blood and are covered by a continuous layer of syncytiotrophoblasts. Two different lineages of undifferentiated cytotrophoblastic stem cells differentiate into villous and interstitial cytotrophoblastic cells. Syncytiotrophoblastic cells secrete pregnancy-associated hormones, including hCG and progesterone. hCG is a glycoprotein hormone and shares a common a-subunit with $\mathrm{LH}$ and FSH. hCG is produced by placental syncytiotrophoblasts after implantation in a process modulated by the partial pressure of oxygen, the presence of reactive oxygen species, and potassium channels [13]. It stimulates progesterone production, decidualization, angiogenesis, and cytotrophoblast differentiation [59]. $K_{v} 1.5$ and $K_{v} 2.1$ are classic delayed rectifier $K_{V}$ channels that are sensitive to oxygen and TEA [7]. These channels are expressed in the syncytiotrophoblast. Díaz et al. [13] reported that the expression oxygen-sensitive $K_{v}$ channels could be downregulated under hypoxic conditions ( $1 \%$ $\mathrm{PO}_{2}$ ) and lead to lower hCG secretion from the placenta. Oxidative stress mediates $\mathrm{hCG}$ secretion and $\mathrm{K}^{+}$permeability, and the regulation of this mechanism depends on the partial pressure of oxygen [13].

Other potassium channels, including $K_{v} 9.3$, Kir6.1, TASK1 , and $\mathrm{BK}_{\mathrm{Ca}}$ channels are expressed in the human placental vasculature. It was also reported that all calcium-activated potassium channels $\left(\mathrm{BK}_{\mathrm{Ca}}, \mathrm{K}_{\mathrm{Ca}}\right.$ and $\mathrm{SK}_{\mathrm{Ca}}$ ) and $\mathrm{K}_{\mathrm{V}}$ channels are expressed in the smooth muscle cells of chorionic plate resistance arteries (CPAs) $[60,61]$. The low-resistance feto-placental circulation and vasodilatation are essential for the suc- 


\section{Obstetrics \& Gynecology Science}

Jun-Mo Kim, et al. $\mathrm{K}$ channels in female reproductive system

cessful maintenance of pregnancy. Local vasodilators such as NO, prostacyclin, and endothelium-derived hyperpolarizing factors (EDHFs) mediate vasorelaxation [62-64]. EDHFs are as potent as $\mathrm{NO}$ and prostaglandin as blood pressure regulators. Endothelial intermediate and small-conductance $\mathrm{K}_{\mathrm{Ca}}$ channels ( $\left(\mathrm{K}_{\mathrm{Ca}_{\mathrm{a}}}\right.$ and $\mathrm{SK}_{\mathrm{Ca}_{\mathrm{a}}}$ ) are major components of EDHFs [65]. IK $\mathrm{K}_{\mathrm{Ca}}$ and $\mathrm{SK}_{\mathrm{Ca}}$ are primarily expressed in the endothelial and smooth muscle cells of placental CPAs. In the endothelium, these channels may play a more important role in vascular function. Endothelial $\mathrm{K}^{+}$currents were observed to be inhibited in hypoxic conditions owing to the downregulation of $\mathrm{IK}_{\mathrm{Ca}}$ and $\mathrm{SK}_{\mathrm{Ca}}$ expression in the ovine uterine arteries and in porcine coronary arteries $[66,67]$. Endothelium-derived NO may regulate $\mathrm{IK}_{\mathrm{Ca}}$ - and $\mathrm{SK}_{\mathrm{Ca}}$-dependent vasodilatation; the expression of endothelial nitric oxide synthase (NOS) and inducible NOS was observed to be significantly downregulated in women with preeclampsia. Therefore, the abnormal expression or dysregulation of IK and SK channels in the endothelium and smooth muscle cells of CPAs, NO, and EDHFs may play a crucial role in the pathogenesis of preeclampsia [62]. In human placental mitochondria, the potassium channel is formed by the subunit Kir6.1, which contributes to placental mitochondrial steroidogenesis by facilitating cholesterol uptake and intermembrane translocation through a mechanism independent of the transport of $\mathrm{K}^{+}$ions inside the mitochondria [68].

\section{Conclusion}

This mini-review provides insight into the roles of potassium channels, which form the largest and most diverse ion channel family, in the relaxation of smooth muscle cells and vasodilatation via the regulation of cell membrane potential as well as in specialized cellular functions, such as the regulation of female sex hormone secretion, relaxation of uterine muscles in pregnancy, turnover into labor, and the successful maintenance of pregnancy mediated by the regulation of vascular tone in placental CPAs. Among the ATP-sensitive potassium channels, Kir6.1/SUR2B in GCs and Kir6.2/SUR1 expressed in GnRH neurons in the hypothalamus modulate progesterone release and a negative feedback mechanism. All 5 types of potassium channels are expressed in uterine myometrium. Calcium-activated potassium channels play a major role in the relaxation of smooth muscles in nonpregnant state as well as in early to mid-term pregnancy.
Other channels affect the transition from uterine quiescence to active myometrial contractions in late pregnancy, including voltage-activated and rapidly-gating sodium-activated potassium channels. The prevention of hypoxia in the placenta is important for treating preeclampsia. Endothelial intermediate- and small-conductance calcium-activated potassium channels mediate the vasodilatation of placental CPAs via the secretion of NO and EDHFs.

\section{Acknowledgements}

This work was supported by grants from the Korean Society of Obstetrics and Gynecology and NIH NIDDK RO1DK099284 (TW). We thank Ms. Leah Sanders for editing this paper and Dr. Bin Zhang, from Nanjing Medical University, Jiangsu China, for providing Fig. 2.

\section{Conflict of interest}

No potential conflict of interest relevant to this article was reported.

\section{Ethical approval}

This study does not require approval of the Institutional Review Board because no patient data is contained in this article. The study was performed in accordance with the principles of the Declaration of Helsinki.

\section{Patient consent}

Written informed consent and the use of images from patients are not required for the publication.

\section{References}

1. Aronson PS, Giebisch G. Effects of pH on potassium: new explanations for old observations. J Am Soc Nephrol 2011;22:1981-9.

2. Gumz ML, Rabinowitz L, Wingo CS. An integrated view 


\section{Obstetrics \& Gynecology Science}

Vol. 63, No. 5, 2020

of potassium homeostasis. N Engl J Med 2015;373:60-72.

3. Palmer BF. Regulation of potassium homeostasis. Clin J Am Soc Nephrol 2015;10:1050-60.

4. DuBose TD Jr. Regulation of potassium homeostasis in CKD. Adv Chronic Kidney Dis 2017;24:305-14.

5. Kunz L, Richter JS, Mayerhofer A. The adenosine 5'-triphosphate-sensitive potassium channel in endocrine cells of the human ovary: role in membrane potential generation and steroidogenesis. J Clin Endocrinol Metab 2006;91:1950-5.

6. Comes N, Serrano-Albarrás A, Capera J, Serrano-Novillo C, Condom E, Ramón Y Cajal S, et al. Involvement of potassium channels in the progression of cancer to a more malignant phenotype. Biochim Biophys Acta 2015;1848 10 Pt B:2477-92.

7. Burg ED, Remillard CV, Yuan JX. K+ channels in apoptosis. J Membr Biol 2006;209:3-20.

8. Hebert SC. An ATP-regulated, inwardly rectifying potassium channel from rat kidney (ROMK). Kidney Int 1995;48:1010-6.

9. Tian C, Zhu R, Zhu L, Qiu T, Cao Z, Kang T. Potassium channels: structures, diseases, and modulators. Chem Biol Drug Des 2014;83:1-26.

10. Kuang Q, Purhonen P, Hebert H. Structure of potassium channels. Cell Mol Life Sci 2015;72:3677-93.

11. Wareing M, Greenwood SL. Review: potassium channels in the human fetoplacental vasculature. Placenta 2011;32 Suppl 2:S203-6.

12. Brainard AM, Korovkina VP, England SK. Potassium channels and uterine function. Semin Cell Dev Biol 2007;18:332-9.

13. Díaz P, Sibley CP, Greenwood SL. Oxygen-sensitive K+ channels modulate human chorionic gonadotropin secretion from human placental trophoblast. PLoS One 2016;11:e0149021.

14. Hummitzsch K, Anderson RA, Wilhelm D, Wu J, Telfer $E E$, Russell $D L$, et al. Stem cells, progenitor cells, and lineage decisions in the ovary. Endocr Rev 2015;36:65-91.

15. Engel S, Klusmann H, Ditzen B, Knaevelsrud C, Schumacher $\mathrm{S}$. Menstrual cycle-related fluctuations in oxytocin concentrations: a systematic review and meta-analysis. Front Neuroendocrinol 2019;52:144-55.

16. Kunz L, Thalhammer A, Berg FD, Berg U, Duffy DM, Stouffer RL, et al. Ca2+-activated, large conductance $\mathrm{K}+$ channel in the ovary: identification, characterization, and functional involvement in steroidogenesis. J Clin Endocrinol Metab 2002;87:5566-74.

17. Mayerhofer A, Föhr KJ, Sterzik K, Gratzl M. Carbachol increases intracellular free calcium concentrations in human granulosa-lutein cells. J Endocrinol 1992;135:153-9.

18. Mayerhofer A, Sterzik K, Link H, Wiemann M, Gratzl M. Effect of oxytocin on free intracellular $\mathrm{Ca} 2+$ levels and progesterone release by human granulosa-lutein cells. J Clin Endocrinol Metab 1993;77:1209-14.

19. Copland JA, Zlatnik MG, Ives KL, Soloff MS. Oxytocin receptor regulation and action in a human granulosalutein cell line. Biol Reprod 2002;66:1230-6.

20. Traut MH, Berg D, Berg U, Mayerhofer A, Kunz L. Identification and characterization of $\mathrm{Ca} 2+$-activated $\mathrm{K}+$ channels in granulosa cells of the human ovary. Reprod Biol Endocrinol 2009;7:28.

21. Gross SA, Newton JM, Hughes FM Jr. Decreased intracellular potassium levels underlie increased progesterone synthesis during ovarian follicular atresia. Biol Reprod 2001;64:1755-60.

22. Fujita R, Kimura S, Kawasaki S, Watanabe $S$, Watanabe $\mathrm{N}$, Hirano $\mathrm{H}$, et al. Electrophysiological and pharmacological characterization of the K(ATP) channel involved in the $\mathrm{K}+$-current responses to FSH and adenosine in the follicular cells of Xenopus oocyte. J Physiol Sci 2007;57:51-61.

23. Chien EK, Zhang Y, Furuta H, Hara M. Expression of adenosine triphosphate-sensitive potassium channel subunits in female rat reproductive tissues: overlapping distribution of messenger ribonucleic acid for weak inwardly rectifying potassium channel subunit 6.1 and sulfonylurea-binding regulatory subunit 2. Am J Obstet Gynecol 1999;180:1121-6.

24. Agoston A, Kunz L, Krieger A, Mayerhofer A. Two types of calcium channels in human ovarian endocrine cells: involvement in steroidogenesis. J Clin Endocrinol Metab 2004;89:4503-12.

25. Kunz L, Rämsch R, Krieger A, Young KA, Dissen GA, Stouffer RL, et al. Voltage-dependent $K+$ channel acts as sex steroid sensor in endocrine cells of the human ovary. J Cell Physiol 2006;206:167-74.

26. Zhang C, Bosch MA, Levine JE, Rønnekleiv OK, Kelly MJ. Gonadotropin-releasing hormone neurons express K(ATP) channels that are regulated by estrogen and responsive to glucose and metabolic inhibition. J Neurosci 


\section{Obstetrics \& Gynecology Science}

Jun-Mo Kim, et al. $\mathrm{K}$ channels in female reproductive system

2007;27:10153-64

27. Huang W, Acosta-Martínez M, Levine JE. Ovarian steroids stimulate adenosine triphosphate-sensitive potassium (KATP) channel subunit gene expression and confer responsiveness of the gonadotropin-releasing hormone pulse generator to KATP channel modulation. Endocrinology 2008;149:2423-32.

28. Ashcroft FM, Gribble FM. New windows on the mechanism of action of K(ATP) channel openers. Trends Pharmacol Sci 2000;21:439-45.

29. Kelly MJ, Rønnekleiv OK, Ibrahim N, Lagrange AH, Wagner EJ. Estrogen modulation of $\mathrm{K}(+)$ channel activity in hypothalamic neurons involved in the control of the reproductive axis. Steroids 2002;67:447-56.

30. Pielecka-Fortuna J, DeFazio RA, Moenter SM. Voltagegated potassium currents are targets of diurnal changes in estradiol feedback regulation and kisspeptin action on gonadotropin-releasing hormone neurons in mice. Biol Reprod 2011;85:987-95.

31. Norberg R, Campbell R, Suter KJ. Ion channels and information processing in $\mathrm{GnRH}$ neuron dendrites. Channels (Austin) 2013;7:135-45.

32. Vastagh C, Solymosi N, Farkas I, Liposits Z. Proestrus differentially regulates expression of ion channel and calcium homeostasis genes in $\mathrm{GnRH}$ neurons of mice. Front Mol Neurosci 2019;12:137.

33. Yin Z, Li Y, He W, Li D, Li H, Yang Y, et al. Progesterone inhibits contraction and increases TREK-1 potassium channel expression in late pregnant rat uterus. Oncotarget 2017;9:651-61.

34. Yin Z, Sada AA, Reslan OM, Narula N, Khalil RA. Increased MMPs expression and decreased contraction in the rat myometrium during pregnancy and in response to prolonged stretch and sex hormones. Am J Physiol Endocrinol Metab 2012;303:E55-70.

35. Aaronson PI, Sarwar U, Gin S, Rockenbauch U, Connolly $M$, Tillet $A$, et al. A role for voltage-gated, but not $\mathrm{Ca} 2+$-activated, $\mathrm{K}+$ channels in regulating spontaneous contractile activity in myometrium from virgin and pregnant rats. Br J Pharmacol 2006;147:815-24.

36. Wang SY, Yoshino M, Sui JL, Wakui M, Kao PN, Kao CY. Potassium currents in freshly dissociated uterine myocytes from nonpregnant and late-pregnant rats. J Gen Physiol 1998;112:737-56.

37. Benkusky NA, Fergus DJ, Zucchero TM, England SK.
Regulation of the Ca2+-sensitive domains of the maxi$\mathrm{K}$ channel in the mouse myometrium during gestation. J Biol Chem 2000;275:27712-9.

38. Pérez $\mathrm{G}$, Toro L. Differential modulation of large-conductance KCa channels by PKA in pregnant and nonpregnant myometrium. Am J Physiol 1994;266:C1459-63.

39. Benkusky NA, Korovkina VP, Brainard AM, England SK. Myometrial maxi-K channel beta1 subunit modulation during pregnancy and after 17beta-estradiol stimulation. FEBS Lett 2002;524:97-102.

40. Okawa T, Longo M, Vedernikov YP, Chwalisz K, Saade GR, Garfield RE. Role of nucleotide cyclases in the inhibition of pregnant rat uterine contractions by the openers of potassium channels. Am J Obstet Gynecol 2000;182:913-8.

41. Sadlonova V, Franova S, Dokus K, Janicek F, Visnovsky J, Sadlonova J. Participation of BKCa2+ and KATP potassium ion channels in the contractility of human term pregnant myometrium in in vitro conditions. J Obstet Gynaecol Res 2011;37:215-21.

42. Ferreira JJ, Butler A, Stewart R, Gonzalez-Cota AL, Lybaert $\mathrm{P}, \mathrm{Amazu} \mathrm{C}$, et al. Oxytocin can regulate myometrial smooth muscle excitability by inhibiting the $\mathrm{Na}+$ -activated K+ channel, Slo2.1. J Physiol 2019;597:13749.

43. Curley M, Cairns MT, Friel AM, McMeel OM, Morrison $\mathrm{J}$, Smith TJ. Expression of mRNA transcripts for ATPsensitive potassium channels in human myometrium. Mol Hum Reprod 2002;8:941-5.

44. Smith RC, McClure MC, Smith MA, Abel PW, Bradley $\mathrm{ME}$. The role of voltage-gated potassium channels in the regulation of mouse uterine contractility. Reprod Biol Endocrinol 2007;5:41.

45. Modzelewska B, Kostrzewska A, Sipowicz M, Kleszczewski T, Batra S. Apamin inhibits NO-induced relaxation of the spontaneous contractile activity of the myometrium from non-pregnant women. Reprod Biol Endocrinol 2003;1:8.

46. Noble K, Floyd R, Shmygol A, Shmygol A, Mobasheri A, Wray $S$. Distribution, expression and functional effects of small conductance Ca-activated potassium (SK) channels in rat myometrium. Cell Calcium 2010;47:47-54.

47. Rosenbaum ST, Larsen T, Joergensen JC, Bouchelouche PN. Relaxant effect of a novel calcium-activated potassium channel modulator on human myometrial 


\section{Obstetrics \& Gynecology Science}

Vol. 63, No. 5, 2020

spontaneous contractility in vitro. Acta Physiol (Oxf) 2012;205:247-54.

48. Jensen BS, Hertz M, Christophersen P, Madsen LS. The Ca2+-activated $\mathrm{K}+$ channel of intermediate conductance:a possible target for immune suppression. Expert Opin Ther Targets 2002;6:623-36.

49. Bond CT, Sprengel R, Bissonnette JM, Kaufmann WA, Pribnow D, Neelands $T$, et al. Respiration and parturition affected by conditional overexpression of the $\mathrm{Ca} 2+$-activated K+ channel subunit, SK3. Science 2000;289:1942-6.

50. Rosenbaum ST, Svalø J, Nielsen K, Larsen T, Jørgensen JC, Bouchelouche P. Immunolocalization and expression of small-conductance calcium-activated potassium channels in human myometrium. J Cell Mol Med 2012;16:3001-8.

51. Rahbek M, Nazemi S, Odum L, Gupta S, Poulsen SS, Hay-Schmidt $A$, et al. Expression of the small conductance Ca2+-activated potassium channel subtype 3 (SK3) in rat uterus after stimulation with $17 \beta$-estradiol. PLoS One 2014;9:e87652.

52. Greenwood IA, Tribe RM. Kv7 and Kv11 channels in myometrial regulation. Exp Physiol 2014;99:503-9.

53. Gutman GA, Chandy KG, Adelman JP, Aiyar J, Bayliss DA, Clapham DE, et al. International Union of Pharmacology. XLI. Compendium of voltage-gated ion channels: potassium channels. Pharmacol Rev 2003;55:583-6.

54. McCallum LA, Pierce SL, England SK, Greenwood IA, Tribe RM. The contribution of Kv7 channels to pregnant mouse and human myometrial contractility. J Cell Mol Med 2011;15:577-86.

55. Greenwood IA, Yeung SY, Tribe RM, Ohya S. Loss of functional $\mathrm{K}+$ channels encoded by ether-à-go-go-related genes in mouse myometrium prior to labour onset. J Physiol 2009;587:2313-26.

56. Heyman NS, Cowles CL, Barnett SD, Wu YY, Cullison C, Singer CA, et al. TREK-1 currents in smooth muscle cells from pregnant human myometrium. Am J Physiol Cell Physiol 2013;305:C632-42.

57. Buxton IL, Heyman N, Wu YY, Barnett S, Ulrich C. A role of stretch-activated potassium currents in the regulation of uterine smooth muscle contraction. Acta Pharmacol
$\operatorname{Sin} 2011 ; 32: 758-64$

58. Yin Z, He W, Li Y, Li D, Li H, Yang Y, et al. Adaptive reduction of human myometrium contractile activity in response to prolonged uterine stretch during term and twin pregnancy. Role of TREK-1 channel. Biochem Pharmacol 2018;152:252-63.

59. Weedon-Fekjær MS, Taskén K. Review: Spatiotemporal dynamics of hCG/CAMP signaling and regulation of placental function. Placenta 2012;33 Suppl:S87-91.

60. Brereton MF, Wareing M, Jones RL, Greenwood SL. Characterisation of $\mathrm{K}+$ channels in human fetoplacental vascular smooth muscle cells. PLoS One 2013;8:e57451.

61. Wareing M, Bai X, Seghier F, Turner CM, Greenwood $S L$, Baker PN, et al. Expression and function of potassium channels in the human placental vasculature. Am J Physiol Regul Integr Comp Physiol 2006;291:R437-46.

62. Li FF, He MZ, Xie Y, Wu YY, Yang MT, Fan Y, et al. Involvement of dysregulated IKCa and SKCa channels in preeclampsia. Placenta 2017;58:9-16.

63. Kang KT. Endothelium-derived relaxing factors of small resistance arteries in hypertension. Toxicol Res 2014;30:141-8.

64. Choi SK, Hwang JY, Lee J, Na SH, Ha JG, Lee HA, et al. Gene Expression of Heme Oxygenase-1 and Nitric Oxide Synthase on Trophoblast of Preeclampsia. Korean J Obstet Gynecol 2011;54:341-8.

65. Köhler R, Hoyer J. The endothelium-derived hyperpolarizing factor: insights from genetic animal models. Kidney Int 2007;72:145-50.

66. Zhu R, Hu XQ, Xiao D, Yang S, Wilson SM, Longo LD, et al. Chronic hypoxia inhibits pregnancy-induced upregulation of SKCa channel expression and function in uterine arteries. Hypertension 2013;62:367-74.

67. Yang Q, Huang JH, Man YB, Yao XQ, He GW. Use of intermediate/small conductance calcium-activated potassium-channel activator for endothelial protection. J Thorac Cardiovasc Surg 2011;141:501-10.

68. Milan R, Flores-Herrera O, Espinosa-Garcia MT, OlveraSanchez S, Martinez F. Contribution of potassium in human placental steroidogenesis. Placenta 2010;31:860-6. 